\title{
ERRATUM
}

\section{Erratum to: Establishment of reference ranges for ductus venosus waveform indices in the Japanese population}

\author{
Yasuhiro Takahashi $\cdot$ Keisuke Ishii • \\ Keisuke Honda $\cdot$ Akira Kikuchi · \\ Koichi Takakuwa $\cdot$ Kenichi Tanaka
}

Published online: 3 July 2013

(C) The Japan Society of Ultrasonics in Medicine 2013

Erratum to: J Med Ultrasonics (2010) 37:201-207

DOI 10.1007/s10396-010-0269-4

The original version of this article unfortunately contained an error. In the "Results" section of the main text, in the final sentence of the second paragraph, the formula for the $\mathrm{a} / \mathrm{S}$ of the ductus venosus was incorrect. The correct formula is as follows:

$$
\begin{aligned}
\mathrm{a} / \mathrm{S}= & \left(-0.00014 \times \mathrm{GA}^{2}+0.01512 \times \mathrm{GA}+0.4392\right. \\
& +K \times 0.08787)^{10 / 7}
\end{aligned}
$$

The online version of the original article can be found under doi:10.1007/s10396-010-0269-4.

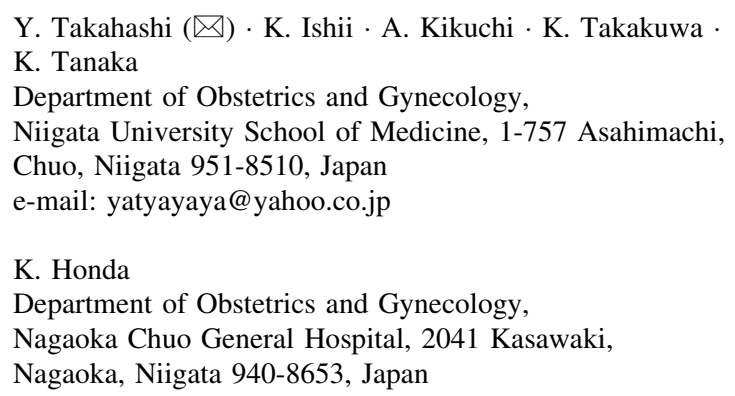

